\title{
Severe hypernatremia in children after surgical resection of hepatic echinococcosis: a rare and potentially fatal complication
}

\author{
Kewei Li ${ }^{1}$, Yijun Liu'², Xiaolong Xie ${ }^{1}$, Rongxing Zhou ${ }^{3}$ and Bo Xiang ${ }^{1 *}$ (D)
}

\begin{abstract}
Background: Using effective scolicidal agents intraoperatively is essential to lessen the recurrence rate of hepatic echinococcosis. However, severe hypernatremia may occur after hypertonic saline (HS) has been applied as the scolicidal agent. The aim of this study is to report on pediatric patients with severe hypernatremia after hepatic echinococcus surgery.
\end{abstract}

Methods: Patients who presented to West China Hospital between January 2010 and February 2017 were retrospectively analyzed. Children under 16 years with echinococcosis treated by resection were included in the study.

Results: A total of 26 children were enrolled in this study, including 16 boys and 10 girls with a median age of 8 (2-16). 24 (92.3\%) cases were cystic echinococcosis (CE) and two (7.7\%) were alveolar echinococcosis (AE). According to Clavien-Dindo classification of surgical complications, the complication rate of all 26 patients was $19.2 \%$, among which three cases belonged to Grade I, one to Grade III b and 1 to Grade IV. Two children encountered severe hypernatremia (sodium: $155.3 \mathrm{mmol} / \mathrm{L}$ and $190.0 \mathrm{mmol} / \mathrm{L}$ ). Data showed classic clinical features of severe hypernatremia: profound and persistent bradycardia, hypotension and coma. After treatment, they recovered well without any neurologic sequelae. All patients were followed up regularly for a median time of 38 months (range 4-89 months); the overall disease-free survival was $100.0 \%$.

Conclusions: HS irrigation of intra-abdominal echinococcosis may cause acute hypernatremia and severe consequences. Diagnostic suspicion and early intervention are vital tools for avoiding morbidity and mortality.

Keywords: Hypernatremia, Children, Liver resection, Echinococcosis

\section{Background}

Echinococcosis is a severe helminthic zoonosis caused by the adult or larval tapeworm of Echinococcus (E) granulosus, E. mulitilocularis, E. vogeli or E. oligarthrus; it most frequently involves the liver (50-70\%) [1]. The

\footnotetext{
*Correspondence: xb_edu_2116@163.com

'Department of Pediatric Surgery, West China Hospital of Sichuan University, 610041 Chengdu, China

Full list of author information is available at the end of the article
}

two major species of medical and public health significance that bring about hepatic echinococcosis are E. granulosus and E. multilocularis, which cause cystic echinococcosis (CE) and alveolar echinococcosis (AE), respectively. $\mathrm{AE}$ is mainly distributed in the northern hemisphere, while CE prevails worldwide [2].

Surgery is the main mode of treatment for these diseases. Recurrence during a long-term follow-up is the primary problem with this treatment option. Using

(c) The Author(s). 2021 Open Access This article is licensed under a Creative Commons Attribution 4.0 International License, which permits use, sharing, adaptation, distribution and reproduction in any medium or format, as long as you give appropriate credit to the original author(s) and the source, provide a link to the Creative Commons licence, and indicate if changes were made. The images or other third party material in this article are included in the article's Creative Commons licence, unless indicated otherwise in a credit line to the material. If material is not included in the article's Creative Commons licence and your intended use is not permitted by statutory regulation or exceeds the permitted use, you will need to obtain permission directly from the copyright holder. To view a copy of this licence, visit http://creativecommons.org/licenses/by/4.0/. The Creative Commons Public Domain Dedication waiver (http://creativecommons.org/publicdomain/zero/1.0/) applies to the data made available in this article, unless otherwise stated in a credit line to the data. 
effective scolicidal agents intraoperatively is essential to lessen the recurrence rate in patients with spillage of cyst contents $[3,4]$. Hypertonic saline (HS) is one of the most common scolicidal agents to prevent recurrence on a global scale. HS has been recommended by WHO/ OIE as a scolicidal agent in various concentrations (15$20 \%$ ) with exposure time of at least $15 \mathrm{~min}^{2}$. Iatrogenic hypernatremia, defined by a serum sodium concentration of more than $145 \mathrm{mmol} / \mathrm{L}$, although rare, can occur after HS has been applied as the scolicidal agent of echinococcus [5]. It is noteworthy that hypernatremia is highly associated with mortality (40-60\%) [6] and is particularly fatal in cases in which hypernatremia occurs very rapidly. Here, we report on pediatric patients with severe hypernatremia after hepatic echinococcus surgery, who were treated in the pediatric intensive care unit.

\section{Methods}

\section{Patients}

Between January 2010 and February 2017, patients with echinococcosis treated with operative resection were retrospectively analyzed. The data were collected from patient charts and electronic medical records of the patients with echinococcosis (ICD-10 code B67.5 and B67.8) at West China Hospital of Sichuan University. We included the patients who were diagnosed with echinococcosis from birth to 16 years of age and received resection as a treatment. Our study did not enroll transplantation cases. Written informed consent was obtained from all patients' parents. The data collected included demographic data (sex, age and children from pastoral area), symptoms (vomiting, abdominal pain, diarrhea, distention, constipation, and duration of symptoms), signs (temperature, palpable mass, and location of the mass) and imaging and laboratory data (ultrasonic examination, CT/MRI/MRCP and echinococcus enzyme linked immunosorbent assay (ELISA)). Clinical records were independently reviewed by two authors.

\section{Treatment regimen}

The surgical options included endocystectomy, nonanatomical liver resection, and intra-luminal cholangiohydatid resection. A subcostal incision was employed to ensure adequate exposure of the liver. During the operation, copious viscous fluid and colloid cyst contents were found after lancing the pericystic membrane in most CE cases. After aspiration of the cyst fluid, $20 \%$ HS was injected into the cyst cavity and incubated for $5 \mathrm{~min}$. The HS and cyst contents were then carefully removed, followed by irrigation of $20 \%$ HS into the cyst cavity for $10 \mathrm{~min}$ and, ultimately, normal saline irrigation. For certain stages of $\mathrm{CE}$ and $\mathrm{AE}$ with cystic features, hepatectomy is a necessary approach. All diagnoses were confirmed by histopathological examination of the cases. Hypernatremia was defined as serum sodium level exceeding $145 \mathrm{mmol} / \mathrm{L}$.

\section{Statistical analysis}

All results were expressed as the mean values \pm standard deviations or medians as appropriate. Statistical analysis SPSS software (version 24.0, SPSS Company, Chicago, IL) was used to perform all statistical analyses.

\section{Results}

\section{Patient characteristics}

A total of 26 children were enrolled in this study, including 16 boys and 10 girls with a median age of 8 (2-16). Characteristics of the study population are described in Table 1. Twenty-five (96.2\%) patients were from pastoral areas. Of the children included in this study, eight (30.8\%) had no clinical symptoms, 18 (69.2\%) had mild symptoms (including abdominal pain and discomfort) and none had severe symptoms. Twenty-one (80.8\%) patients had positive results for the echinococcus ELISA test. Based on ultrasound liver images, the WHO classification [7] of lesions included 20 (76.9\%) patients belonging to CL/CE1/CE2, four (15.4\%) patients belonging to CE3 and two $(7.7 \%)$ patients belonging to CE4/CE5. The surgical procedures included endocystectomy in 14 patients, endocystectomy with non-anatomical liver resection in five patients, non-anatomical liver resection in four patients, intra-luminal bile duct mass resection in one patient and endocystectomy in both liver and right

Table 1 Patient characteristics and histopathological features

\begin{tabular}{ll}
\hline Variables & Results \\
\hline Sex (male/female) & $16 / 10$ \\
Age (y) & $2-16$ \\
Children from pastoral area & $25(96.2 \%)$ \\
Children with abdominal symptoms & $18(69.2 \%)$ \\
Echinococcus ELISA positive & $21(80.8 \%)$ \\
WHO classification of ultrasound images & \\
CL、CE1、CE2 & $20(76.9 \%)$ \\
CE3 & $4(15.4 \%)$ \\
CE4、CE5 & $2(7.7 \%)$ \\
Surgical procedure & \\
Endocystectomy & $14(53.8 \%)$ \\
Endocystectomy with non-anatomical hepatectomy & $5(19.2 \%)$ \\
Non-anatomical hepatectomy & $4(15.4 \%)$ \\
Intra-luminal bile duct mass resection & $1(3.8 \%)$ \\
Hepatopulmonary endocystectomy & $2(7.7 \%)$ \\
Histopathological feature & \\
E. granulosus & $24(92.3 \%)$ \\
E. multilocularis & $2(7.7 \%)$ \\
\hline
\end{tabular}

ELISA enzyme linked immunosorbent assay 
lung in two patients. According to constellation of histology findings, 24 (92.3\%) cases were CE and two (7.7\%) were AE.

\section{Postoperative data}

Table 2 presents postoperative results. Ten surgical complications occurred in five patients, including three bile leakages, one episode of bleeding, one unilateral pleural effusion, one ascites, one bronchopleural fistula, two cases of hypernatremia and one reoperation due to intestinal obstruction at one month postoperatively. In addition, temporary elevation of serum transaminases was recorded in 10 patients. The mean serum level of alanine aminotransferase (ALT) and aspartate aminotransferase (AST) were $161.8 \pm 40.6 \mathrm{IU} / \mathrm{L}$ and $176.1 \pm 48.3 \mathrm{IU} / \mathrm{L}$, respectively (Fig. 1. a, b and c). According to the Clavien-Dindo classification of surgical complications, the complication rate of all 26 patients was $19.2 \%$, among which three cases belonged to Grade I, one to Grade III b and one to Grade IV. A median pediatric intensive care unit (PICU) stay of 12.7 (range 0-120) hrs was required, and the mean post-operative length of hospital stay (LOS) was $8.3 \pm 3.6$ days. All patients were followed up regularly for a median time of 38 months (range 4-89 months); the overall disease-free survival was $100.0 \%$.

\section{Data of two children with severe postoperative hypernatremia}

The clinical characteristics of two children with hypernatremia are shown in Table 3 . Patient 1 was a 5 -yearold boy suffering from abdominal pain. He was admitted to hospital for removal of multiple hydatid cysts (CE2m, by WHO classification) with a maximum diameter of $8.6 \mathrm{~cm}$. Endocystectomy and partial liver resection were performed, and the following histologic examination indicated the involvement of E. granulosus. After aspiration of the cysts' contents, a total capacity of $500 \mathrm{~mL}$ $20 \%$ HS was injected into each cyst cavity and left for 15 min, respectively. The fluid was then cautiously removed by an aspirator. The patient subsequently experienced skin rashes, hypotension, anaphylactic shock and hypernatremia (sodium: $155.3 \mathrm{mmol} / \mathrm{L}$ ) (Fig. 1.d) at the end of operation. Hypotonic fluid and $5 \%$ dextrose were infused intravenously. Shortly afterwards, the patient was transferred to the PICU with an endotracheal tube in place. The serum sodium decreased to a normal range on postoperative day (POD) 1, then successful extubation was performed. The patient experienced mild ascites for the next few days. Approximately eight days after surgery, the patient made a swift recovery and was well at follow-up.

Patient 2 was an 11-year-old girl with abdominal distension severe enough to warrant hospital admission, diagnosed as hepatopulmonary hydatid cysts (CE2m, by

Table 2 Postoperative data of patients

\begin{tabular}{ll}
\hline Variables & $\mathbf{n}(\%) /$ Results \\
\hline Bile leakage & $3(11.5)$ \\
Postoperative hemorrhage & $1(3.8)$ \\
Pleural effusion & $1(3.8)$ \\
Ascites & $1(3.8)$ \\
Bronchopleural fistula & $1(3.8)$ \\
Elevation of serum transaminase (ALT vs. AST IU/L) & $10(38.5) / 161.8 \pm 40.6$ vs. $176.1 \pm 48.3$ \\
Hypernatremia(mmol/L) & $2(7.7) / 155.3$ vs. 190.0 \\
Reoperation & $1(3.8)$ \\
Clavien-Dindo classification & \\
Grade I & $3(11.5)$ \\
Grade II & $0(0.0)$ \\
Grade IIla & $0(0.0)$ \\
Grade IIIb & $1(3.8)$ \\
Grade IV & $1(3.8)$ \\
Grade V & $0(0.0)$ \\
Hospital stay(d) & $8.3 \pm 3.6$ \\
Follow-up(m) & $38(4-89)$ \\
Disease free survival & $26(100)$ \\
\hline
\end{tabular}

ALT alanine aminotransferase; AST aspartate aminotransferase 


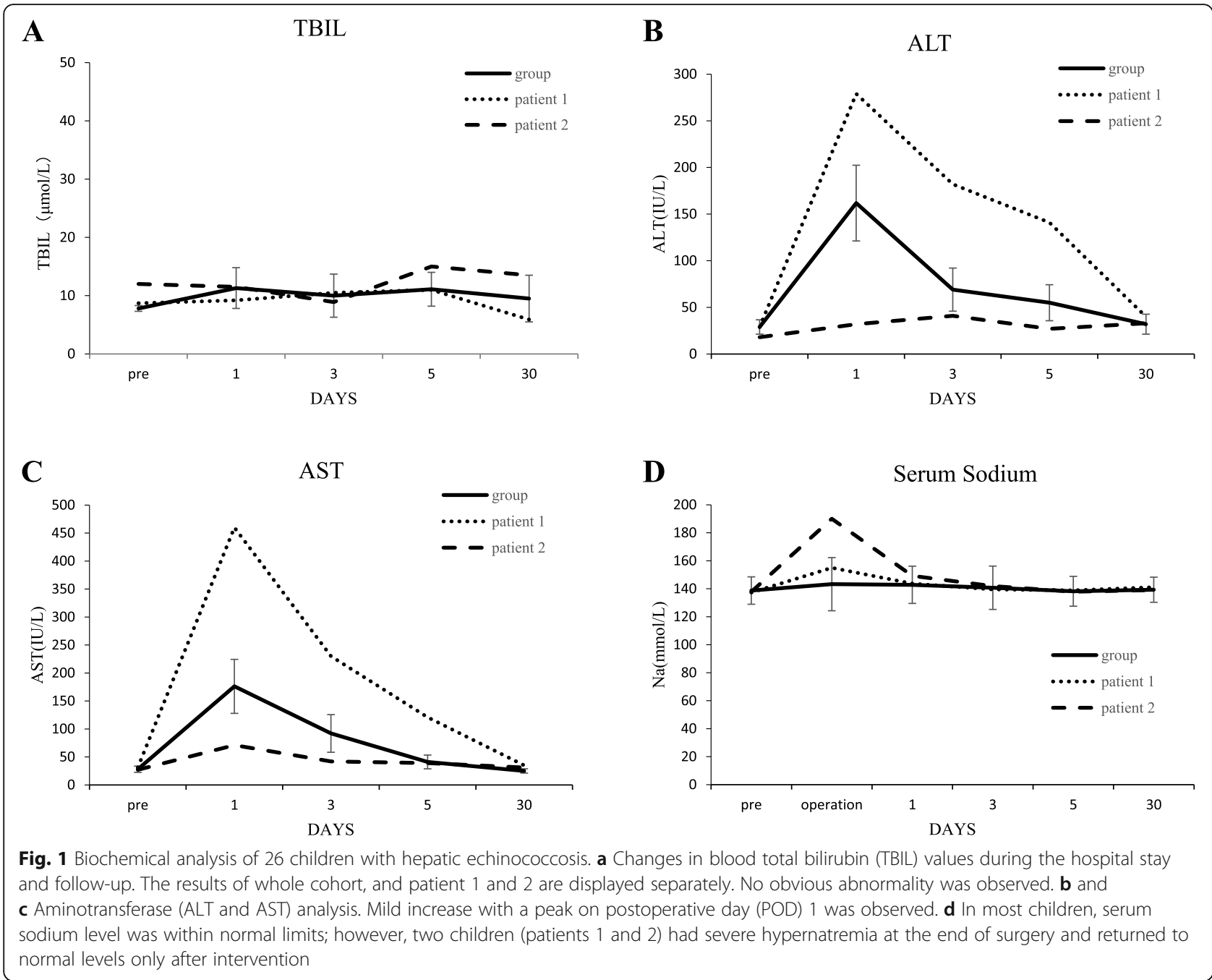

Table 3 Data of 2 patients with postoperative hypernatremia

\begin{tabular}{lll}
\hline Variables & Patient $\mathbf{1}$ & Patient $\mathbf{2}$ \\
\hline Age $(\mathrm{y})$ & 5 & 11 \\
Sex & M & F \\
Number of cysts & Multiple & 2 \\
Maximum diameter of Cyst(cm) & 8.6 & 10 \\
WHO classification & CE2m & CE2m \\
Surgical procedure & Endocystectomy and partial liver resection & Endocystectomy \\
Histopathological feature & E. granulosus & E. granulosus \\
Peak serum sodium (mmol/L) & 155.3 & 190 \\
Blood transfusion & 0 & 0 \\
Complication & Mild ascites & Bile leakage and bronchopleural fistula \\
PICU stay (h) & 18 & 120 \\
Postoperative hospital stay (d) & 8 & 19 \\
\hline
\end{tabular}


WHO classification) with a maximum diameter of $10 \mathrm{~cm}$, located on the liver and superior lobe of the right lung. The patient underwent endocystectomy and CE was then confirmed by thorough histologic examination. After aspiration of the cysts' contents, a total capacity of $800 \mathrm{~mL} 20 \%$ HS was injected into each cyst cavity and left for $15 \mathrm{~min}$. The patient experienced a delayed recovery after general anesthesia, suffering from postoperative hypernatremia (sodium: 190.0mmol/L) (Fig. 1.d), and immediately underwent tracheal intubation and was transferred to the PICU. Hypotonic fluid and 5\% dextrose were administered intravenously, and sodium decreased to a normal range on POD 2. Successful extubation was performed on POD 2. However, the patient developed bile leakage and bronchopleural fistula. On POD 3, the patient became unresponsive and bradycardic (heart rate: $55-60$ beats per minute), although all serum electrolytes were within normal limits at that time. She was re-intubated for one day. Successful reextubation was performed on POD 4, and afterwards, the patient returned to general recovery ward on POD 5. After biliary and thoracic drainage, the patient recovered well and was discharged from hospital 19 days postoperatively without any neurologic sequelae.

\section{Discussion}

Although no clinical trial exists to compare the safety and effectiveness of all the various therapeutic protocols in the management of liver hydatid disease, including surgical resection, percutaneous puncture, drug therapy and employment of a watch-and-wait surveillance policy, surgical resection accounts for the most common treatment approach, particularly in patients with large cysts, multiple daughter vesicles or treatment complexity [8].

Given the risk of death and obliterative cholangitis induced by formalin and biliary epithelium injury following the use of silver nitrate, HS is one of the most common and essential scolicidal agents in the world to prevent inadvertent dissemination and avoid recurrence, and is the agent recommended by the WHO/OIE [5]. The effect of HS is attributed to lysis in response to sufficiently strong osmotic gradient across the outer cuticular membrane of the scolex [4]. Although HS has been used in various concentrations $(3-30 \%)$ for various exposure regimens (5-30 $\mathrm{min}$ ) according to reports in the literature, and recommended by the WHO/OIE in various concentrations (15-20\%) using an exposure time of at least $15 \mathrm{~min}$, there is no clear consensus on the optimal concentration or exposure time as far as scolicidal effect is concerned [4].

Iatrogenic hypernatremia is routinely caused by the administration of large doses of sodium bicarbonate (e.g. during a circulatory arrest or intoxication) and HS perfusion (e.g. during stomach lavage, artificial abortion or echinococcosis cyst irrigation); hypernatremia can at times be the result of ingesting large amount of high-salt diet [9-12].

The mechanism of hypernatremia after a HS injection during surgery of echinococcosis may involve: absorption through the cyst wall, absorption from the digestive tract via a cyst communication with the biliary ducts (suggested by bile-stained cyst contents), spillage of HS in the peritoneum or pleura, or unwitting injection of HS into hepatic blood vessels [13, 14]. In our study, hypernatremia might have resulted from absorption of HS through cyst walls, and via the exchange activity of both salt and water across the peritoneal membrane and pleura.

Life-threatening hypernatremia causes plasma water volume expansion and intracellular water volume reduction; hence it causes cerebral dehydration and pulmonary edema with convulsions and coma as clinically critical sequelae [8]. Data from our patients showed classic clinical features of severe hypernatremia: profound and persistent bradycardia, hypotension and coma [15]. As mentioned in the literature, among patients who had sodium concentrations above $160 \mathrm{mmol} / \mathrm{L}$ for various causes, the mortality rate was $70 \%$; children tolerated more severe hypernatremia and had better prognoses compared to adults [8]. Few patients in the literature have experienced and survived extreme hypernatremia with serum sodium level greater than $200 \mathrm{mmol} / \mathrm{L}$; most of them were children $[16,17]$.

Although severe hypernatremia was reported in the English literature in only a few cases after HS therapy, mortality has occurred in at least three patients thus far (see Table 4) [5, 8, 13], including one child reported by Krige et al. This 7-year-old boy died from iatrogenic hypernatremia with a serum sodium level of $170 \mathrm{mmol} /$ L after hepatic hydatid surgery. Among these deaths, two adult patients underwent laparoscopic endocystectomy / partial cystectomy. Diego Anta et al. observed that laparoscopic technique may cause severe or fatal hypernatremia as frequently or more frequently than open operation [18]. Some studies concluded that increased intra-abdominal pressure increases distribution and diffusion of intraperitoneal chemotherapy (with oxaliplatin and cisplatin) in the visceral and parietal peritoneum of an experimental animal model $[19,20]$. This constitutes a potential mechanism for fatal hypernatremia in laparoscopic cases. However, no study directly addresses the use of HS under elevated intraabdominal pressure.

Acute hypernatremia should be treated more carefully. However, optimal correction rate of acute hypernatremia in children has not been established. Based on experimental data on cerebral volume regulation, a faster pace of correction, such as decreasing serum sodium concentration by $1 \mathrm{mmol} / \mathrm{l} / \mathrm{h}$, as we practiced, was suggested 
Table 4 World mortality reports of Echinococcosis with postoperative hypernatremia

\begin{tabular}{|c|c|c|c|c|c|c|c|c|c|c|}
\hline Authors & Year & Region & $\operatorname{Age}(y)$ & Sex & $\begin{array}{l}\text { Surgical } \\
\text { type }\end{array}$ & $\begin{array}{l}\text { Saline } \\
\text { concentration }\end{array}$ & $\begin{array}{l}\text { Volume } \\
\text { (ml) }\end{array}$ & $\begin{array}{l}\text { Exposure time } \\
\text { (min) }\end{array}$ & $\begin{array}{l}\text { Peak serum } \mathrm{Na} \\
(\mathrm{mmol} / \mathrm{L})\end{array}$ & $\begin{array}{l}\text { Postoperative } \\
\text { survival }\end{array}$ \\
\hline Krige et al. [13] & 2002 & $\begin{array}{l}\text { South } \\
\text { africa }\end{array}$ & 7 & M & $E$ & $20 \%$ & 250 & 5 vs. 3 & 170 & $20 \mathrm{~h}$ \\
\hline $\begin{array}{l}\text { Michalodimitrakis } \\
\text { et al. [8] }\end{array}$ & 2011 & Greece & 38 & $F$ & LPC & $15 \%$ & 4000 & NA & 196 & $3 w$ \\
\hline Zeng et al. [5] & 2017 & China & 28 & $\mathrm{~F}$ & LE & $20 \%$ & 300 & 10 & 188.8 & $5 d$ \\
\hline
\end{tabular}

Na sodium; E endocystectomy; LPC laparoscopic partial cystectomy; LE laparoscopic endocystectomy

for hypernatremia of rapid onset [21, 22]. Even after an intraoperative upward serum sodium shift of $60 \mathrm{mmol} / \mathrm{l}$, a prompt and rational correction of hypernatremia may be in alignment with survival without neurologic sequelae and improve the patient prognosis [21].

Our experience over 26 pediatric cases of operative treatment of echinococcosis indicated that the HS irrigation during operation of echinococcosis may cause hypernatremia with a potentially fatal outcome. Encouragingly, our rapid therapeutic interventions were successful, and mortality was avoided. To our knowledge, this is the first retrospective study on severe hypernatremia in children after surgical resection of hepatic echinococcosis. Our study is inevitably limited by small sample size and lack of a control group. More rigorous experimental protocols should be designed to offer opportunities for prevention and treatment.

\section{Conclusions}

HS irrigation of intra-abdominal echinococcosis may cause acute hypernatremia leading to morbidity and mortality. Diagnostic suspicion and early intervention in the PICU are vital tools for avoiding devastating clinical outcomes. Further studies are needed to achieve a better understanding of postoperative hypernatremia in pediatric patients.

\section{Abbreviations}

E: Echinococcus; CE: Cystic echinococcosis; AE: Alveolar echinococcosis; HS: Hypertonic saline; ELISA: Enzyme linked immunosorbent assay; ALT: Alanine aminotransferase; AST: Aspartate aminotransferase; PICU: Pediatric intensive care unit; POD: Postoperative day; Na: Sodium; LPC: Laparoscopic partial cystectomy; LE: Laparoscopic endocystectomy

\section{Acknowledgements}

This work was supported by grant from Science \&Technology Support Project of Sichuan Province (2019YFS0371). The authors would also like to thank our patient' parents for their assistance with data collection. Meanwhile, we appreciate Ellen L Larson, William Cao and Abu Rmilah Anan A. for their excellent advice.

\section{Authors' contributions}

KWL designed the study and wrote the article; YJL did the data analysis and wrote the article; XLX provided the data and wrote the article; RXZ reviewed the data and the manuscript; BX drafted the article and made critical revisions of the manuscript; All authors approved the final manuscript as submitted and agree to be accountable for all aspects of the work.
Funding

All phases of this study were funded by the Science \&Technology Support Project of Sichuan Province, grant number: 2019YFS0371. The funding agency did not have any impact on the study design, data analysis, writing the manuscript or the decision to publish this manuscript.

Availability of data and materials

The datasets are available from the corresponding author on reasonable request.

\section{Declarations}

\section{Ethics approval and consent to participate}

This study was approved by the Regional Ethics Committee of our hospital, and due to its retrospective nature, informed consent was waived. The administrative permission was acquired by our team to access the data used in our research.

\section{Consent for publication}

Written informed consent was obtained from the patients' parents/guardians to publish this study.

Competing interests

The authors have no conflicts of interest relevant to this article to disclose.

\section{Author details}

'Department of Pediatric Surgery, West China Hospital of Sichuan University, 610041 Chengdu, China. ${ }^{2}$ West China School of Medicine of Sichuan University, Chengdu, China. ${ }^{3}$ Department of biliary surgery, West China Hospital of Sichuan University, Chengdu, China.

Received: 9 June 2020 Accepted: 11 March 2021

Published online: 24 March 2021

\section{References}

1. Ozogul B, Kisaoglu A, Atamanalp SS, Ozturk G, Aydinli B, Yildirgan Ml, et al. Splenic Hydatid Cysts: 17 Cases. Indian J Surg. 2015;77(Suppl 2):257-60.

2. Eckert, J, Gemmell, M. A, Meslin, François-Xavier, Pawlowski, Z. S \& World Health Organization. (2001). WHO/OIE manual on echinococcosis in humans and animals: a public health problem of global concern / edited by J. Eckert ... et al.]. Paris, France:World Organisation for Animal Health. https://apps. who.int/iris/handle/10665/42427.

3. Kayaalp C, Balkan M, Aydin C, Ozgurtas T, Tanyuksel M, Kirimlioglu V, et al. Hypertonic saline in hydatid disease. World I Surg. 2001;25(8):975-9.

4. Atalay F, Kirimlioglu V, Gundogdu H, Akincioglu T, Gencer A. Surgery for hydatid cysts of the liver. Hiroshima J Med Sci. 1995:44(4):89-92.

5. Zeng R, Wu R, Lv Q, Tong N, Zhang Y. The association of hypernatremia and hypertonic saline irrigation in hepatic hydatid cysts: A case report and retrospective study. Med (Baltim). 2017;96(37):e7889.

6. Muhsin SA, Mount DB. Diagnosis and treatment of hypernatremia. Best Pract Res Clin Endocrinol Metab. 2016:30(2):189-203.

7. Group WHOIW. International classification of ultrasound images in cystic echinococcosis for application in clinical and field epidemiological settings. Acta Trop. 2003:85(2):253-61

8. Michalodimitrakis M, Nathena D, Mavroforou A, Papavdi A, Kranioti EF. Fatal hypernatraemia after laparoscopic treatment of hydatid liver cyst: medical and legal concerns of a rare complication. Forensic Sci Int. 2012;219(1-3): e16-8. 
9. Conde MP, Rodriguez MA, Lopez JM, Gonzalez-Porras JR. Thrombosis secondary to acute hypernatraemia after liver hydatid cyst surgery. Blood Coagul Fibrinolysis. 2015;26(6):695-8.

10. Wanninayake HM, Brough W, Bullock N, Calne RY, Farman JV. Hypernatraemia after treatment of hydatid. Br Med I (Clin Res Ed). 1982; 284(6325):1302-3.

11. Johr M, Berger TM, Winiker $H$. Unexpected hypernatremia during pulmonary resection in a 7-year-old child with hydatid disease. Paediatr Anaesth. 2006; 16(6):697-8.

12. Furukawa S, Takaya A, Nakagawa T, Sakaguchi I, Nishi K. Fatal hypernatremia due to drinking a large quantity of shoyu (Japanese soy sauce). J Forensic Leg Med. 2011;18(2):91-2.

13. Krige JE, Millar AJ, Rode $H$, Knobel D. Fatal hypernatraemia after hypertonic saline irrigation of hepatic hydatid cysts. Pediatr Surg Int. 2002;18(1):64-5.

14. Belghiti J, Benhamou JP. Houry S, Grenier P. Huguier M, Fekete F. Caustic sclerosing cholangitis. A complication of the surgical treatment of hydatid disease of the liver. Arch Surg. 1986;121(10):1162-5.

15. Feig PU, McCurdy DK. The hypertonic state. N Engl J Med. 1977;297(26): 1444-54.

16. Moder KG, Hurley DL. Fatal hypernatremia from exogenous salt intake: report of a case and review of the literature. Mayo Clin Proc. 1990;65(12): 1587-1594.

17. Finberg L, Kiley J, Luttrell CN. Mass accidental salt poisoning in infancy. A study of a hospital disaster. JAMA. 1963:184:187-90.

18. Anta D, Belena JM, Alvarez R, Nunez M. Effects of pneumoperitoneum on severe hypernatremia in an adult patient who underwent laparoscopic surgery of hydatid cysts. J Clin Anesth. 2017;37:52-4.

19. Facy O, Al Samman S, Magnin G, Ghiringhelli F, Ladoire S, Chauffert B, et al. High pressure enhances the effect of hyperthermia in intraperitoneal chemotherapy with oxaliplatin: an experimental study. Ann Surg. 2012; 256(6):1084-8.

20. Esquis $P$, Consolo D, Magnin G, Pointaire P, Moretto P, Ynsa MD, et al. High intra-abdominal pressure enhances the penetration and antitumor effect of intraperitoneal cisplatin on experimental peritoneal carcinomatosis. Ann Surg. 2006;244(1):106-12

21. Albi A, Baudin F, Matmar M, Archambeau D, Ozier Y. Severe hypernatremia after hypertonic saline irrigation of hydatid cysts. Anesth Analg. 2002;95(6): 1806-8. table of contents.

22. Adrogue HJ, Madias NE. Hypernatremia. N Engl J Med. 2000;342(20):1493-9.

\section{Publisher's Note}

Springer Nature remains neutral with regard to jurisdictional claims in published maps and institutional affiliations.

Ready to submit your research? Choose BMC and benefit from:

- fast, convenient online submission

- thorough peer review by experienced researchers in your field

- rapid publication on acceptance

- support for research data, including large and complex data types

- gold Open Access which fosters wider collaboration and increased citations

- maximum visibility for your research: over $100 \mathrm{M}$ website views per year

At $\mathrm{BMC}$, research is always in progress.

Learn more biomedcentral.com/submissions 